\title{
A Multidimensional Mixed Ordered-Response Model for Analyzing Weekend Activity Participation
}

\section{Chandra R. Bhat and Sivaramakrishnan Srinivasan}

The University of Texas at Austin, Department of Civil Engineering,

1 University Station C1761, Austin, Texas 78712-0278

Tel: 512-471-4535, Fax: 512-475-8744,

Email: bhat@mail.utexas.edu,s.siva@mail.utexas.edu

Paper \# 149-03 


\section{ABSTRACT}

The objective of this paper is to examine the frequency of participation of individuals in out-of-home non-work and non-school episodes over the weekend. A multivariate mixed ordered response formulation accommodating the effects of explanatory variables and capturing the dependence among the propensity to participate in different activity types is presented and applied using a San Francisco Bay area travel survey conducted in 2000. The results indicate the important effects of household sociodemographics (income, household structure, and bicycle ownership), individual sociodemographics (age, employment status, gender, and availability of driver's license), internet use, location effects, and day of week/seasonal effects. Interestingly, the results show that motorized vehicle ownership and urban form characteristics of the individual's neighborhood (land-use mix and density) do not have a statistically significant effect on stop-making propensity for any of the activity purposes. The lack of effects of these variables may be due to self-selection of individuals and households into neighborhoods based on their travel preferences. That is, individuals and households may locate themselves based on their motorized vehicle ownership preferences and mobility preferences. In addition to the effect of several variables on stop-making, the model also reveals substitution and complementarity effects among different activity types due to unobserved factors.

Keywords: Multivariate mixed ordered response, weekend activity participation, activity-travel patterns, simulated maximum likelihood, day of week and season effects. 


\section{INTRODUCTION}

The last decade has seen the emergence of the activity-based modeling approach as not only a behaviorally sound paradigm to analyze travel behavior, but also as a viable and implementable approach to forecasting travel demand (see Bhat and Koppelman, 1999; Pendyala and Goulias, 2002, and Arentze and Timmermans, 2004). Specifically, several operational analytic frameworks within the activity analysis paradigm have been formulated, and some metropolitan areas have even implemented these frameworks (Waddell et al., 2002 and Castiglione et al., 2003).

While there has been substantial progress in the development and implementation of activity-based travel analysis efforts, almost all (if not all) of these efforts have focused on weekday activity-travel patterns. Even within the context of weekday activity-travel patterns, much emphasis has been placed on the patterns of workers (for example, see Bhat and Singh, 2000; Hamed and Mannering, 1993; Strathman, 1994; Mahmassani et al., 1997; Pendyala et al., 2002). However, the recognition that the analysis of non-worker activity-travel behavior also provides important input to transportation planning has led to an increasing focus on the activitytravel behavior of non-workers. For example, the frameworks of Bowman and Ben-Akiva (2000) and Kitamura and Fujii (1998) are applicable to both workers and non-workers. Bhat and Singh, (2000), Bhat and Misra (2001), and Misra et al. (2003), on the other hand, emphasize the fundamental differences in the underlying factors and mechanisms influencing the activity and travel-related decisions of workers and non-workers, and propose exclusive frameworks for modeling the activity-travel decisions of workers and non-workers. But all these frameworks have examined worker and non-worker activity-travel behavior only on weekdays. 
The objective of this paper is to examine the activity travel patterns of individuals on weekend days. To our knowledge, this is the first study to adopt an activity-based model framework to examine weekend activity episode participation. Bhat and Gossen (2004) analyzed weekend activity participation behavior, but restricted their attention to only recreational episodes. Besides, their analysis was rather specific and focused on the substitutions between inhome and out-of-home recreational activities. Parsons Brinckerhoff Quade and Douglas (PBQD) Inc., (2000) analyzed the dimensions of weekend travel, and compared and contrasted weekend and weekday travel. While providing several useful insights into weekend travel, the PBQD study was focused on a descriptive examination of travel patterns and not on modeling the activity-travel patterns as a function of relevant attributes of the activity-travel environment and individual/household demographics.

The motivation for the focus on weekend non-work and non-school activity-travel patterns in this paper is multifold. First, weekend travel has been increasing over time and constitutes approximately 26\% of total trips during the week (Federal Highway Administration and Bureau of Transportation Statistics, 1995). Thus, the average percentage of total weekly trips during a weekend day ( $=26 / 2$ or $13 \%$ ) is about the same as the average percentage of total weekly trips during a weekday (= $74 / 5$ or $15 \%$ ). This conclusion is also corroborated by the PBQD study in the New York metropolitan area, which found that the household daily person trip rate during the weekends (about 8 trips/household) is not substantially lower than that during the weekdays (between 8 to 9 trips/household). As expected, the PBQD study also found that the non-work person trip rate is higher on weekends than on the average weekday. Second, the PBQD study observed that about half of all weekend trips are undertaken during the midday period (10 a.m.-4 p.m.), compared to only about a third of all weekday trips undertaken during 
the same period. In an analysis of weekend activity-travel patterns in the San Francisco Bay area, Lockwood et al. (2003) also found that the volume of trips is consistently high and spread out during the midday hours of the weekend day. Such a high, sustained, level of traffic can contribute to traffic congestion and air quality problems, especially to the latter because vehicle starts during periods of high temperatures can lead to high emission rates. Third, the average trip distance is longer on weekend days compared to weekdays. According to the PBQD study in the New York metropolitan area, the average weekend day trip distance is 7.8 miles, while the average weekly trip distance is 7.1 miles. This, along with the trip rates discussed earlier, suggests a person miles of travel rate of 63.2/household on the average weekend day compared to 58.9-63.2/household on an average weekday. Thus, in terms of daily person miles of travel, each weekend day contributes more than or about the same as a weekday. Though this result in terms of person miles of travel does not translate to vehicle miles of travel (VMT), the important point is that weekend activities and travel also warrant careful attention for transportation planning and air quality analysis (Lockwood et al., 2003 estimate the weekend day VMT to be about $80 \%$ of the weekday VMT; the lower weekend day VMT is because of higher automobile occupancy rates for weekend trips).

To summarize, the analysis of weekend activities and their associated travel will facilitate the good design/planning of transportation systems, and the reliable evaluation of urban management policies directed toward traffic congestion alleviation and air quality improvement. The analysis of weekend activity-travel patterns is particularly important because the congested network links during the weekends may not be the same as the congested links during the weekdays. Further, and perhaps not unrelated to the above point, air quality violations for ozone 
are extending into the weekend days in many metropolitan areas. The focus on weekend activitytravel patterns in the current paper is motivated by the above considerations.

The rest of this paper is structured as follows. The next section discusses a representation and analysis framework for weekend activity travel patterns. Section 3 develops the mathematical formulation for one component of the weekend activity travel analysis framework focusing on the frequency of weekend day stop-making. Section 4 discusses the data and sample used in the empirical analysis of the paper. Section 5 presents the estimation results. Finally, Section 6 concludes the paper by summarizing the findings and identifying future research directions.

\subsection{REPRESENTATION AND ANALYSIS FRAMEWORK FOR INDIVIDUAL WEEKEND ACTIVITY-TRAVEL PATTERNS}

\subsection{Representation Scheme}

The representation analysis framework proposed here for weekend activity-travel patterns is based on Bhat and Misra’s (2001) framework for non-workers on weekdays. The framework has the following salient characteristics: 1) It considers all the relevant activity-travel attributes of individual weekend patterns, 2) It includes both the generation and scheduling of activity episodes, 3) It considers time as an all-encompassing continuous entity within which individuals make activity/travel decisions, and 4) It does not require the a priori designation of activity episodes as fixed or flexible or primary or secondary. The framework represents individual weekend day activity-travel patterns as a series of out-of-home activity episodes (or stops) of different types interspersed with periods of in-home activity stays (the term "stops" is used to refer to out-of-home activity episodes in the rest of this paper; the chain of stops between two inhome activity episodes is referred to as a tour). 
The characterization of the weekend daily activity travel pattern is accomplished by identifying a number of different attributes within the pattern. The attributes are classified on the basis of the level of representation with which they are associated; that is, whether they are associated with the entire daily pattern, a tour in the day, or an episode. Pattern-level attributes include the number of stops of each activity type and the sequencing of all episodes (both stops and in-home episodes). The only tour-level attribute is the travel mode for the tour. Episode-level attributes include the episode duration, travel time to the episode from the previous episode, and the location of out-of-home episodes (i.e., stops). Finally, in the representation scheme, it is assumed that 3 a.m. is the start of the day and that all individuals are at home during the start of the day.

\subsection{Analysis Framework}

The joint modeling of all the attributes of the representation scheme discussed in the earlier section is infeasible because of the large number of attributes and the large number of possible choice alternatives for each attribute. There is a need to develop an analytic framework to model the representation that is feasible to implement from a practical standpoint.

The analysis approach proposed here considers the pattern-level attributes first, followed by the tour-level attribute of mode choice, and finally the episode-level attributes (see Figure 1). The underlying basis for such a framework is that the decisions regarding pattern-level attributes are driven by the basic activity needs of the individual (and the household of which the individual is a part). Consequently, and consistent with the derived demand philosophy of the activity-based approach, the pattern-level decisions are considered to be at the highest level of the analysis hierarchy. In contrast, decisions regarding the episode-level attributes tend to be 
driven primarily by scheduling convenience, short-term temporal constraints, and travel conditions. Therefore, these attributes are relegated to the lowest level of the analysis hierarchy. The tour-level attribute of travel mode choice is positioned at the intermediate level of the analysis hierarchy since it affects the attributes of all out of-home episodes within the tour (note that while the hierarchy in Figure 1 is shown as a top down sequence, feedback can be allowed from the bottom up).

The pattern-level attributes may be modeled using a system of two model components (Figure 1). The first component is associated with the generation of the number of non-work/nonschool stops of each activity type during the weekend day. A possible mathematical structure for this component is a multivariate ordered response mechanism that recognizes the interdependence in stop-making across different activity types. The second model component for the pattern-level attributes focuses on the sequencing of stops and the determination of the placement of in-home episodes in the activity-travel pattern. The tour and episode-level attributes may be modeled using the econometric structures identified in Figure 1.

In this paper, the focus is on the first model component (STOPS model) associated with the pattern-level attributes for weekend activity-travel patterns (Figure 1). In the next section, a mathematical structure for the STOPS model is presented and an estimation approach is proposed.

A point to note here. The analysis framework in Figure 1 applies to the vast majority of individuals who do not travel to work/school over the weekends. For the small fraction of individuals who travel to work/school, the analysis can proceed by determining whether or not an individual pursues an out-of-home work/school activity and then using this information to determine non-work and non-school stop generation. Thus, in the current analysis, we consider work/school participation and total duration of the participation as explanatory variables in the non- 
work/non-school activity episode generation model. The estimations of the work/school participation and duration model that would be a precursor to the non-work/non-school activity model estimated in this paper is beyond the scope of the current research.

\section{MODEL STRUCTURE AND ESTIMATION}

\subsection{Mathematical Formulation}

For presentation ease, we develop the mathematical formulation for stop generation with only three activity purposes. Extension to any number of activity purposes is conceptually and mathematically straightforward. It has to be noted that the estimation and empirical results in the current paper are associated with stop generation for seven activity purposes and not three.

Let $q$ be an index for individuals, and let $l, m$, and $n$ be the indices for number of stops for each of the three activity purposes $(q=1,2, \ldots, Q ; l=1,2, \ldots, L ; m=1,2, \ldots, M ; n=1,2, \ldots, N)$. In the usual ordered-response framework notation, we write the latent propensity to participate in each activity purpose as a function of relevant independent variables and relate this latent propensity to the observed discrete number of stops through threshold bounds (see Bhat and Singh, 2000 for a discussion of the appropriateness of an ordered response structure for the modeling of number of stops; McKelvey and Zavonia, 1975 appear to be the first to have proposed an ordered response structure in the econometrics literature). The equation system takes the following form:

$$
\begin{aligned}
& f_{q}^{*}=\alpha^{\prime} x_{q}+\varepsilon_{q}+u_{q}, f_{q}=l \text { if } \delta_{l-1}<f_{q}^{*}<\delta_{l} \\
& g_{q}^{*}=\beta^{\prime} y_{q}+\eta_{q}+v_{q}, g_{q}=m \text { if } \theta_{m-1}<g_{q}^{*}<\theta_{m} \\
& h_{q}^{*}=\gamma^{\prime} z_{q}+\xi_{q}+w_{q}, \quad h_{q}=n \text { if } \psi_{n-1}<h_{q}^{*}<\psi_{n}
\end{aligned}
$$

where $f_{q}^{*}, g_{q}^{*}$, and $h_{q}^{*}$ are the latent stop-making propensities for the three activity purposes; $x_{q}$, $y_{q}$, and $z_{q}$ are independent variables and $\alpha, \beta$, and $\gamma$ are corresponding coefficient vectors to 
be estimated; $\varepsilon_{q}, \eta_{q}$, and $\xi_{q}$ are jointly multivariate normal distributed with a mean vector of zeros and a covariance matrix $\Sigma\left(\varepsilon_{q}, \eta_{q}\right.$, and $\xi_{q}$ are identically and independently distributed across individuals); and $u_{q}, v_{q}$, and $w_{q}$ are standard logistic error terms independent of one another, and identically and independently distributed across individuals. The $\delta, \theta$, and $\psi$ parameters represent threshold bounds, and $f_{q}, g_{q}$, and $h_{q}$ are the observed number of stops of each activity purpose pursued by individual $q$.

The covariance matrix of the error terms $u_{q}, v_{q}$, and $w_{q}$ may be written as follows:

$$
\Sigma=\left[\begin{array}{ccc}
1 & A_{12} & A_{13} \\
& 1 & A_{23} \\
& & 1
\end{array}\right],
$$

where the off-diagonal terms capture the error covariance across the different activity purposes; that is, they capture the effect of common unobserved factors influencing stop-making propensity of different purposes. Thus, if $A_{12}$ is positive, it implies that individuals with a higher than average propensity in their peer group to participate in the first activity purpose are also likely to have a higher than average propensity to participate in the second activity purpose. The reader will note that the diagonal terms in Equation (2) are set to one to normalize the scale, which is unidentified in the ordered response model. Consequently, $\Sigma$ represents a correlation matrix. Of course, if all the correlation parameters (off-diagonal elements of $\Sigma$ ) are identically zero, the model system in Equation (1) would collapse to independent mixed ordered logit models for each activity purpose. The independent mixed ordered logit models are not structurally different from the standard ordered response logit models (the scale difference because of the addition of $\varepsilon_{q}, \eta_{q}$, and $\xi_{q}$ in the mixed ordered logit model will lead to different magnitudes of parameters in the independent mixed ordered logit and standard ordered logit 
models, but the substantive interpretations and relative magnitudes will remain the same). In the general case when $\Sigma$ is not diagonal, Equation system (1) corresponds to a multivariate mixed ordered logit structure. To our knowledge, this is the first paper to consider a multivariate mixed ordered response structure for modeling more than three dimensions (though for the purpose of exposition of the formulation, we use only three dimensions). In the case of three dimensions or less, a multivariate ordered response probit is feasible to estimate analytically since most software routines have reasonably accurate algorithms to evaluate trivariate normal cumulative distributions (see Scott and Kanaroglou, 2002). But in more than three dimensions, simulated maximum likelihood or Bayesian techniques need to be used. In this paper, we use a maximum simulated likelihood approach for estimation based on recent advances in quasi-Monte Carlo simulation methods.

\subsection{Maximum Simulated Likelihood (MSL) Estimation}

The parameters to be estimated in the multivariate mixed ordered response system of Equation (1) include the $\alpha, \beta$, and $\gamma$ parameter vectors, the $\delta, \theta$, and $\psi$ thresholds, and the correlation parameters embedded in $\Sigma$. Let $\varphi=\left(\alpha^{\prime}, \beta^{\prime}, \gamma^{\prime}\right)^{\prime}$ and $\omega=\left(\delta^{\prime}, \theta^{\prime}, \psi^{\prime}\right)^{\prime}$. Let $F_{q l}$ be a set of dummy variables that take a value of 1 if the $q^{\text {th }}$ individual is observed to make $l$ stops of the first activity type, and 0 otherwise. Also, define $G_{q m}$ and $H_{q n}$ similarly for the other two activity purposes. Next, define the following:

$$
\begin{aligned}
& L_{f q} \mid \varepsilon_{q}=\prod_{l}\left[\left\{\Lambda\left(\delta_{l}-\left[\alpha^{\prime} x_{q}+\varepsilon_{q}\right]\right)-\Lambda\left(\delta_{l-1}-\left[\alpha^{\prime} x_{q}+\varepsilon_{q}\right)\right\}^{F_{q l}}\right]\right. \\
& L_{g q} \mid \eta_{q}=\prod_{m}\left[\left\{\Lambda\left(\theta_{m}-\left[\beta^{\prime} y_{q}+\eta_{q}\right]\right)-\Lambda\left(\theta_{m-1}-\left[\beta^{\prime} y_{q}+\eta_{q}\right)\right\}_{q m}^{G_{q m}}\right]\right. \\
& L_{h q} \mid \xi_{q}=\prod_{n}\left[\left\{\Lambda\left(\psi_{n}-\left[\gamma^{\prime} z_{q}+\xi_{q}\right]\right)-\Lambda\left(\psi_{n-1}-\left[\gamma^{\prime} z_{q}+\xi_{q}\right)\right\}^{H}\right]\right.
\end{aligned}
$$


where $\Lambda$ represents the cumulative standard logistic distribution. Then the likelihood function for individual $q$ conditioned on $\varepsilon_{q}, \eta_{q}$, and $\xi_{q}$ may be written as:

$$
L_{q} \mid \varepsilon_{q}, \eta_{q}, \xi_{q}=\left(L_{f q} \mid \varepsilon_{q}\right)\left(L_{g q} \mid \eta_{q}\right)\left(L_{h q} \mid \xi_{q}\right) \text {. }
$$

The unconditional likelihood for individual $q$ may be written as:

$$
L_{q}=\int_{\varepsilon_{q}} \int_{\eta_{q}} \int_{\xi_{q}}\left(L_{q} \mid \varepsilon_{q}, \eta_{q}, \xi_{q}\right) \phi_{3}\left(\varepsilon_{q}, \eta_{q}, \xi_{q}\right) d \varepsilon_{q} d \eta_{q} d \xi_{q},
$$

where $\phi_{3}$ is the trivariate standard density function. The log-likelihood function is finally $L=\sum_{q} \ln L_{q}$. The dimensionality of the integration in the above equation is equal to 3 in the case of three activity purposes. More generally, the dimensionality is equal to the total number of purposes in the modeling context under consideration. In the current paper, we consider stop generation in each of seven non-work activity purposes over the weekend, resulting in a seven dimensional integral in the likelihood function for each individual. Such large dimensional integration cannot be accomplished using general purpose numerical methods such as quadrature, since quadrature techniques cannot evaluate the integrals with sufficient precision and speed for estimation via maximum likelihood (see Hajivassiliou and Ruud, 1994). We apply simulation techniques to approximate the integrals in the individual-specific likelihood function and maximize the sum (across individuals) of the logarithm of the resulting individual-specific simulated likelihood functions with respect to the parameters to be estimated. This is achieved by computing the integrand in Equation (5) at different realizations of $\varepsilon_{q}, \eta_{q}$, and $\xi_{q}$ drawn from a multivariate normal distribution, and by averaging over the different values of the integrand across the different realizations. Under rather weak regularity conditions, the maximum (log) simulated likelihood (MSL) estimator is consistent, asymptotically efficient, and asymptotically normal (see Hajivassiliou and Ruud, 1994; Lee, 1992). 
In the current paper, we use a quasi-Monte Carlo (QMC) method to draw realizations for $\varepsilon_{q}, \eta_{q}$, and $\xi_{q}$ from their population multivariate normal distribution. Specifically, we use 150 draws of the Halton sequence in the current analysis. Details of the Halton sequence and the procedure to generate this sequence are available in Bhat (2001).

One additional point needs discussion here. The Halton draws do not reflect the desired correlation matrix $\Sigma$ of the multivariate distribution of $\varepsilon_{q}, \eta_{q}$, and $\xi_{q}$. Rather, they are univariate draws for each dimension. To translate the univariate Halton draws to multivariate Halton draws, we apply the Cholesky decomposition of the correlation matrix $\Sigma$ to the univariate draws. In addition, to ensure the positive-definitiveness of the correlation matrix, we parameterize the likelihood function in terms of the elements of the Cholesky decomposedmatrix of $\Sigma$ rather than using the elements of $\Sigma$ directly. This procedure guarantees the positivedefinitiveness of $\Sigma$, but raises two new issues. One is that the unit values along the diagonal of $\Sigma$ have to be enforced. This is achieved by appropriately parameterizing the diagonal elements of the Cholesky decomposition matrix. Thus, we write the $\Sigma$ matrix in the three dimensional example (see Equation 2) as:

$$
\Sigma=\left[\begin{array}{ccc}
1 & A_{12} & A_{13} \\
A_{12} & 1 & A_{23} \\
A_{13} & A_{23} & 1
\end{array}\right]=S^{\prime} S=\left[\begin{array}{ccc}
1 & 0 & 0 \\
S_{12} & \sqrt{1-S_{12}^{2}} & 0 \\
S_{13} & S_{23} & \sqrt{1-S_{13}^{2}-S_{23}^{2}}
\end{array}\right]\left[\begin{array}{ccc}
1 & S_{12} & S_{13} \\
0 & \sqrt{1-S_{12}^{2}} & S_{23} \\
0 & 0 & \sqrt{1-S_{13}^{2}-S_{23}^{2}}
\end{array}\right]
$$

This parameterization of the Cholesky decomposition matrix S'S guarantees unit values along the diagonal of $\Sigma$. The parameters estimated then in $S$ are $S_{12}, S_{13}$, and $S_{23}$ in the threedimensional case (extension to more dimensions is straightforward). The second issue arising from the parameterization of the likelihood function in terms of the Cholesky decomposition of $\Sigma$ is that we only get the sampling covariance matrix of the elements of the Cholesky decomposition matrix, not the sampling covariance matrix of the elements of $\Sigma$. The sampling 
covariance matrix of the elements of $\Sigma$ can be computed by either (a) using a Taylor series approximation method applied to the sampling covariance matrix of the Cholesky decomposition of $\Sigma$ or (b) using the convergent values of the Cholesky decomposition matrix, generating the equivalent convergent values of $\Sigma$, and running the MSL procedure with the likelihood function parameterized directly with respect to the elements of $\Sigma$. For obvious reasons, the MSL procedure will converge without any iterations in the second approach, but the net result is that we immediately get the sampling covariance matrix of the elements of $\Sigma$ as the output from the “maximization” procedure. In the current paper, we use the second approach.

\section{DATA SOURCE AND SAMPLE FORMATION}

\subsection{Data Sources}

The primary data source used for this analysis is the San Francisco Bay Area Travel Survey (BATS) conducted in 2000. This survey was designed and administered by MORPACE International Inc. for the Bay Area Metropolitan Transportation Commission. The survey collected information on all activity and travel episodes undertaken by individuals from over 15,000 households in the Bay Area for a two-day period (see MORPACE International Inc., 2002 for details on survey, sampling, and administration procedures). However, each individual provided information on only one weekend day in the survey (i.e., individuals were surveyed on Friday and Saturday or Sunday and Monday, but not Saturday and Sunday). The information collected on activity episodes included the type of activity (based on a 17-category classification system), the name of the activity participation location (for example, Jewish community center, Riverpark plaza, etc.), the type of participation location (such as religious place, or shopping mall), start and end times of activity participation, and the geographic location of activity 
participation. Travel episodes were characterized by the mode used, and the start and end times of travel. Furthermore, data on individual and household sociodemographics, individual employment-related characteristics, household auto ownership, and internet access and usage were also obtained. A secondary data source obtained from the Metropolitan Transportation Commission provided zonal-level land-use and demographics data for each of the Traffic Analysis Zones (TAZ).

\subsection{Sample Formation}

The process of generating the sample for the analysis involved several steps. First, only individuals 5 years or older were considered for the analysis. Children in the age group of 0 to 4 years may influence the activity participation behavior of other household members, but need the assistance of other household members to themselves participate in out-of-home activities. Second, all weekend out-of-home activity episodes were selected from the original survey data. Third, weekend travel episodes that began and ended at home without any stops in-between (for example, walking or bicycling around the neighborhood) were identified, labeled as "pure recreation” activity episodes, and appended to the file from Step 2. Fourth, only non-work and non-school activity episodes were selected from the out-of-home activity episode file by removing episodes with the activity type labels of "work or work-related” and "school or schoolrelated”. The non-work and non-school activity episodes in the resulting file belong to one of fifteen activity purposes. Fifth, the 15-activity purpose classification was aggregated to a 5activity purpose typology: (1) social-recreational (including meals, hobbies and exercising, conversation and visiting family/friends, relaxing/resting, and pure recreation), (2) shopping, (3) personal business (banking, personal services, medical appointments, etc.), (4) community 
activities (volunteer, civic, or religious activities), and (5) pick-up/drop-off. Sixth, we disaggregated the social/recreational episodes into two types based on whether or not the episode involved physically active pursuits. The motivation for doing so is that physically active episodes are quite different in their travel and activity attributes compared to physically inactive socialrecreational episodes (see Bhat and Lockwood, 2004). The distinction between physically active and inactive social-recreational episodes was made based on the location type of out-of-home activity participation, which was provided by respondents in the form of an open-ended response. About 10,000 distinct location types were reported in the survey, and these were manually recoded into 450 categories for the analysis. The location type categories considered as being associated with physically active social-recreation are listed in Appendix A. Pure recreation episodes were also categorized as physically active if they involved the use of a nonmotorized mode. Seventh, we disaggregated the shopping category into maintenance and other (non-maintenance) shopping, again because these two categories are quite different in their activity and travel attributes (for example, the mean activity duration for maintenance shopping episodes in the BATS data is 32 minutes, while the mean activity duration for non-maintenance shopping episodes is 60 minutes). The location type variable was used to distinguish between maintenance and other shopping episodes. Location types categorized as maintenance shopping included “dry cleaners/laundry services”, “fruit stand”, “grocery”, and "gas station”. At the end of this seventh step, there are seven distinct non-work and non-school activity type categories: (1) Physically active social-recreational (which we will refer to as physically active recreation in the rest of this paper), (2) Physically inactive social-recreational (which we will refer to as physically inactive recreation in the rest of this paper), (3) Maintenance shopping, (4) Other shopping, (5) Personal business, (6) Community, and (7) Pick-up/drop-off. Next, in the eighth 
step, the episode-level data were aggregated to the person level to determine the number of activity episodes by type for each person for each day of the weekend. Ninth, data on individual, household, and zonal (residence zone) characteristics were appropriately cleaned and added to the person-level file. Finally, several screening and consistency checks were performed and records with missing or inconsistent data were eliminated.

The final sample for analysis included data for 5,545 person days from 5,545 individuals belonging to 2,859 households. About $14 \%$ of the individuals in the sample are aged 5 to 15 years (classified as children) and the rest are 16 years or older (classified as adults). Table 1a provides the distribution of individual participation in episodes by type in the sample across both Saturdays and Sundays (the entries in the table represent the percentage of individuals participating in each number of episodes of each activity type; thus, the first entry of 89.2 indicates that $89.2 \%$ of individuals do not participate in any kind of physically active recreational episodes during the weekend day they reported). The table indicates that physically inactive recreation is the most common activity type undertaken during the weekend, with almost $50 \%$ of individuals in the sample undertaking one or more episodes of this kind. Other (nonmaintenance) shopping is the next most frequently undertaken activity (with $28 \%$ of the individuals in the sample undertaking this activity), followed by maintenance shopping (with 16\% undertaking this activity). Tables $1 \mathrm{~b}$ and $1 \mathrm{c}$ provide the distribution of individual participation in episodes by day of weekend. The numbers in the tables clearly indicate that Saturday is the more dominant weekend day of participation for all activity-purposes, except maintenance shopping (where the percentages are about the same for both weekend days) and community activities (Sunday is the dominant day for community activities because of Sunday 
worship services; note that community activities include volunteer, civic, and religious activities).

\section{EMPIRICAL ANALYSIS}

\subsection{Variable Specification}

Several types of variables were considered in the weekend number of episodes model. These included household sociodemographics, individual sociodemographics, internet-use characteristics, location variables, and day of week/seasonal effects. The household sociodemographic characteristics considered in the specifications included household income, household structure, presence and number of children, number of household vehicles, number of bicycles in the household, household income, and dwelling type. The individual sociodemographic variables, in addition to the usual individual-related variable, included participation in work/school activity during the weekend day and the duration of work/school activity. We attempted continuous, spline, and dummy variable specifications for introducing the impact of work/school activity duration, and found that the dummy variable specification with three dummy variables was best (corresponding to work/school duration of 0-4 hours, 4-8 hours, and greater than 8 hours). The internet-use characteristics in the analysis included indicators for the use of the internet for information seeking, shopping, games, social activity (email, chat rooms, etc.), banking and financial transactions, travel, studying, and listening to music. The location variables included a land-use mix diversity variable (see Bhat and Gossen, 2004 for the development of this measure), fractions of detached and non-detached dwelling units, area type variables classifying zones into one of 4 categories (central business districts, urban, suburban, and rural), and residential density and employment density variables. The first 
variable, the land-use mix diversity variable, is a fraction between 0 and 1 , with values close to 1 representing zones with a richer land-use mix.

Finally, the day of week/seasonal variables capture the day of weekend (Saturday or Sunday) and season of year effects (fall, winter, spring, or summer).

The final model specification was developed through a systematic process of adding variables to the market share model (i.e., the constants only model) and eliminating statistically insignificant variables or combining variables when their effects were not statistically different. This process was guided by intuitive considerations.

\subsection{Empirical Results}

\subsubsection{Overall Measures of Fit}

The log-likelihood value at convergence of the final multivariate mixed ordered response logit (MMORL) model specification is -22155.0 and the log-likelihood value of the independent mixed ordered response logit models for each activity purpose is -22191 (the log-likelihood value at convergence for the independent mixed ordered response model for each activity type with only the threshold parameters and no independent variables is -22801.65). The likelihood ratio test value for comparing the MMORL model with the independent mixed ORL models is 72, which is substantially greater than the critical chi-square value corresponding to the number of parameters in the correlation matrix of the MMORL model (of the 21 correlation parameters possible in the MMORL model, only 8 parameters were retained in the final specification; the critical chi-square value with 8 parameters at the 0.005 level of significance is 21.95 ). Thus, the test between the MMORL and independent mixed ORL models very strongly rejects the absence 
of common unobserved factors affecting the propensity to participate in different activity purposes (we discuss the interpretation of the correlation parameters in detail in Section 5.2.8).

\subsubsection{Interpretation of Model Results}

The observed dependent variables used in the estimation correspond to the number of stops of each activity type. The final specification results of the MMORL choice model are presented in Table 2, which shows the estimated effects of the exogenous variables on the latent propensity of individuals to participate in each activity type. Since all the variables in the model are dummy variables, the relative magnitudes of the coefficients also provide an estimate of the importance of the variables in influencing participation propensities and participation probabilities. The marginal impact of variables on the participation probabilities for each combination of number of episodes across the different activity types varies across individuals because of the non-linear structure of the ordered logit formulation. Aggregate level marginal effects may be computed for each dummy variable by changing the value of the variable to one for the subsample of observations for which the variable takes a value of zero and to zero for the subsample of observations for which the variable takes the value of one. We can then sum the shifts in expected aggregate shares in the two subsamples after reversing the sign of the shifts in the second subsample and compute an effective marginal change in expected aggregate shares in the entire sample due to a change in the dummy variable from 0 to 1 . We are not showing these marginal effects here because there are as many as 12,960 aggregate marginal effects (one for each combination stop category) for each variable. But in Section 5.3, we demonstrate the application of the model due to changes in two variables. In the following sections, we discuss the effect of variables on the latent participation propensities by variable category. 


\subsubsection{Effect of Household Sociodemographics}

In the category of household sociodemographics, the effect of income is captured using dummy variables for different income categories, which enables the accommodation of nonlinear impacts on the propensity to participate in episodes (the dummy variable representation was found to be superior to a continuous linear income effect in our specifications). The results in Table 2 show that household income influences participation in physically inactive recreation, other (non-maintenance) shopping, and pick-up/drop-off activities, but not the remaining activity purposes. As expected, individuals in high-income households have a higher propensity to participate in physically inactive recreation pursuits and non-maintenance shopping because of their higher expenditure potential on these discretionary activities. The same trend is observed for pick-up and drop-off episodes too, though the interpretation here is less obvious. Overall, income affects participation in discretionary and relatively expensive activity pursuits, but does not affect participation in less discretionary and less expensive activity pursuits (such as maintenance shopping, personal business, and physically active recreation).

Household structure also has an impact on stop-making. All the household structure variables apply only to the stop-making of adults in the household, not to the stop-making of children in the household (the latter effects were also tested, but did not turn out to be statistically significant). The results in Table 2 indicate that single parents and adults in nuclear family households are more likely to participate in physically active recreational episodes compared to other households, perhaps due to the joint weekend recreational participation of adults and children in activities such as going to the park or walking around the neighborhood. Individuals who live alone are more likely to participate in recreational activities than other non- 
single parent and non-nuclear family households, a reflection perhaps of fewer household responsibilities. Further, the results indicate that couples are more likely to participate in recreational activities than individuals in "other" household types (returning young adult households, roommate households, and other related individual households), but less likely to participate in recreational activities relative to adults in single-individual, single-parent, and nuclear households. Individuals living alone and adults in couple families also participate more often in shopping, presumably because of less time pressures and fewer household responsibilities compared to individuals in other households. Finally, adults in households with children participate less in maintenance shopping and personal business activities during the weekend and more in community activities and pick-up/drop-off activities. The latter result is to be expected, and reflects the participation of young children in weekend activities, such as birthday parties and soccer games, and the transportation of children to these activities.

The final set of variables under household demographics corresponds to the presence of bicycles in the household. The results indicate that individuals (adults and children) in households with bicycles are more likely to participate in physically active recreational activities. This effect is higher for children than adults. Of course, the positive effect of bicycles on physically active pursuits may be a spurious rather than causal effect. That is, it is at least possible that individuals who are predisposed to a physically active lifestyle will be more likely to own bicycles in the first place.

\subsubsection{Effect of Individual Sociodemographics}

The effect of age is included as a non-linear effect with senior adults (>65 years) serving as the base category. The results show that children have a higher propensity (than other 
individuals) to participate in active recreational pursuits, and a lower propensity to participate in maintenance shopping. Further, they are the ones needing "chauffeuring” to various activities, and this is manifested as a positive coefficient on children for the pick-up/drop-off purpose. Young adults 16-21 years of age also pursue more pick-up and drop-off activities, perhaps to pick-up/drop-off friends after social and recreational engagements. Senior adults (>65 years), on the other hand, are most likely to participate in community-related activities. Adults in the middle ages (31-50 years) are most likely to participate in pick-up/drop-off activities among individuals greater than 21 years of age, a finding that does not have any immediate intuitive interpretation and merits further exploration.

The effect of employment on weekend stop-making is included by distinguishing between full-time, part-time employed, and not employed adults. The results suggest that adults employed full-time are most likely to participate in non-maintenance shopping and personal business activities on the weekend, possibly a reflection of time pressures on weekdays. They are least likely to participate in community activities over the weekend.

In addition to employment status, the decision to participate in work or school activity and the duration of such activities over the weekend day has an influence on non-work activity participation on the weekend day. The results indicate that there are no differences in activity participation propensities for the physically active recreation, physically inactive recreation, maintenance shopping, other shopping and personal business activity types between individuals who do not pursue work/school activity and those that participate in work/school activity for less than 4 hours during the weekend day. However, individuals who participate in work/school activity are less likely to participate in community activities than those who do not participate in work/school activity. Interestingly, individuals with work/school activity over the weekend day 
are more likely to participate in pick-up/drop-off activity if their work duration is less than 8 hours, presumably reflecting pick-up/drop-off stops on the way to/from work/school. For all activity types, participation propensity decreases as the duration of work/school activity increases, as reflected by the negative signs on the dummy variables for "work/school duration 4-8 hours” and “work/school duration greater than 8 hours”.

The race variables suggest no statistically significant differences among different ethnic groups in the propensity to participate in activities, except for isolated effects on maintenance activities and pick-up/drop-off activities. This is a rather surprising result, given that several earlier studies (see Bhat and Gossen, 2004 and Mallett and McGuckin, 2000) have suggested significant variations among racial groups to participate in recreation, social, and shopping activities.

Finally, in the "other individual socio-demographics” subcategory, the results indicate the higher weekend out-of-home activity levels of individuals with a driver's license and the lower activity levels of individuals who are physically challenged. Also, women have a higher likelihood of participation in shopping, personal business, and pick-up/drop-off activities, perhaps because of shouldering more of the maintenance and transportation-related responsibilities of the household.

\subsubsection{Internet-use Characteristics}

The impacts of internet-use characteristics show a higher propensity to participate in nonmaintenance shopping if an adult individual uses the internet for shopping purposes, and a higher propensity to participate in community-oriented activities if an adult individual uses the internet for social chatting. These results may be due to one or both of the following reasons. First, 
internet use might have a complementary impact on stop-making outside the home. Second, the same unobserved shopping orientation/sociability factors may impact both use of the internet and participation in shopping/community activities.

\subsubsection{Location Effects}

Several different location variables were explored in the specifications including land-use mix of residence area, residential and employment density, residential area type variables (CBD, urban, suburban, and rural) and residential county-specific variables. Of these, only the latter two categories of variables turned out to be statistically significant (perhaps due to the correlation among the different sets of variables and/or measurement errors in the continuous land-use mix and density variables due to the coarse nature of zones in the Bay area). The results in Table 2 indicate a higher propensity for participation in weekend physical and non-physical recreation, and a lower propensity for participation in pick-up/drop-off episodes, among households residing in CBD and urban areas relative to households in suburban and rural areas. These results may be a reflection of greater opportunities for recreational activities, and better transit service (leading to less need for transporting children and other household members to/from activities), in CBD/urban areas. The county-specific variables capture "fixed effects" related to county-level differences and do not have a straightforward behavioral interpretation.

\subsubsection{Day of Week and Seasonal Effects}

The results indicate important differences between Saturdays and Sundays in the propensities to participate in episodes. In particular, there is a higher level of participation in outof-home activities for all purposes, except the maintenance shopping and community purposes, 
on Saturdays relative to Sundays. This is reasonable since Sundays serve as a transition day between the weekend and the work week, and many individuals use it as an in-home "rest" day. The propensity to participate in community activities is greater on Sunday than Saturday because of Sunday worship services, as already indicated in Section 4.2.

The seasonal effects reflect a lower propensity to participate in recreational and maintenance shopping during the winters compared to other seasons. Also, there is a higher propensity for adults to undertake pick-up/drop-off episodes in the fall and the spring compared to the winter and summer. Further exploration of these seasonal variations in stop-making would be a useful avenue for future research.

\subsubsection{Threshold Parameters}

The threshold parameters represent the demarcation points on the continuous latent propensity scale that identify different observed discrete values of stop-making. As such, they do not have any substantive behavioral interpretations.

\subsubsection{Correlation Effects}

The correlation effects (and their t-statistics in parentheses) are shown in Table 3 (only the upper diagonal is shown, since the matrix is symmetric). This correlation matrix indicates several statistically significant correlations among the stop-making propensities of different activity types. Specifically, unobserved individual attributes that increase the propensity to participate in physically active recreation reduces the propensities to participate in physically inactive recreation and non-maintenance shopping. That is, individuals predisposed to physically active recreation are less likely to participate in physically inactive recreation and non- 
maintenance shopping (compared to individuals not very predisposed to physically active recreation). This is clear evidence of substitution between physically active recreational participation and the more sedentary discretionary activities. On the other hand, there is a complementary relationship between physically inactive recreational pursuits and participation in all other activity purposes except the physically active recreation and pick-up/drop-off purposes. As expected, there is also a rather high and statistically significant complementary correlation effect between the two types of shopping activities. Finally, there is a very high complementary effect in the participation in community and pick-up/drop-off episodes.

\subsection{Model Application}

The model estimated in this paper can be used to determine the change in the number of stops for each combination of stop categories across the seven different activity types due to changes in independent variables over time. This is particularly important because of changing demographic, employment-related and internet-use trends. For instance, the structure of the household is changing rapidly with an increase in households with no children (Texas State Data Center, 2000). The number of employed individuals in the household is also on the rise and this trend is likely to continue despite the short-term slump due to the economy (U.S. Census Bureau, 1999). Additionally, internet use in general and for shopping in particular has been increasing steadily (see Casas et al., 2001 and the many references therein). Such sociodemographic and other changes will have an effect on weekend stop-making and the model in this paper can be used to assess these impacts and provide reliable information regarding stop-making for input to travel demand and air quality analysis. 
In this paper, we demonstrate the application of the model by studying the effect of two such changes. The first is an increase in the number of full-time employed adults and the second is an increase in internet use for shopping. The increase in the number of full-time employed adults is reflected by randomly selecting current non-employed adults in the sample and designating them as full-time employees so that the number of full-time employees increases by 25\% over the current full-time employment level. As indicated earlier, such a change mirrors the projected increase in employment levels in the U.S. population. With this change, the number of full-time employed adults in the sample increases from 2,780 (50\%) to 3,475 (63\%). The change in internet use for shopping is similarly “implemented” by randomly selecting individuals who do not currently use the internet for shopping and designating them as internet shoppers. The number of internet shoppers increases from 310 (6\%) to 620 (11\%) after the change. The impact of the two changes discussed above is evaluated by modifying exogenous variables to reflect the change, computing revised expected aggregate values for number of stops in each combination category, and then obtaining a percentage change from the baseline estimates.

The reader will observe that there are 12,960 stop combination categories, based on all possible combinations of (a) 3 stop categories for physically active recreation, (b) 6 stop categories for physically inactive recreation, (c) 3 stop categories for maintenance shopping, (d) 5 stop categories for “other” shopping, (e) 4 stop categories for personal business, (f) 3 stop categories for community purposes, and (g) 4 stop categories for pick-up/drop-off (see Table 1 for the stop categories; $3 \times 6 \times 3 \times 5 \times 4 \times 3 \times 4=12,960)$. Obviously, it would be infeasible to present the results for all the 12,960 combination categories here. In this paper, we present the results only for the combinations of the two shopping categories (maintenance and nonmaintenance) by marginalizing the results across all the other activity type categories. 
Table 4 presents the results. In response to both an increase in full-time employed adults and internet shopping, the results show a decrease in the combination categories with zero nonmaintenance shopping stops, and an increase in all other combination categories. It is important to note that the latter increases are because of two separate impacts. One is the increase in the combinations purely because of the shift away from the ' 0 ' category for non-maintenance stops (due to the positive effects of full-time employed adults and internet use for shopping on nonmaintenance stop-making; see Table 2) and the second is due to the complementary effects between the two shopping activity categories generated by the strong positive correlation in unobserved factors between the two categories (see Table 3). The second effect is particularly discernable in Table 4 by noting the higher percentage decrease in the $(0,0)$ category (maintenance shopping stops, non-maintenance shopping stops) compared to the $(1,0)$ and $(2,0)$ categories. Further, the percentages tend to increase when moving from left to right or bottom to top in the table (that is, as one moves toward the south-east end of the matrix for each variable). The independent mixed ordered response models would not be able to reflect this trend because they ignore the complementary effects between the shopping categories. The net result is that the independent models can mis-estimate the effect of changes in independent variables. In fact, one can assess the magnitude of such mis-estimates in the context of the simple application example by computing the net percentage change in shopping stops (both maintenance and nonmaintenance) as follows:

Net \% change in shopping stops $=\sum_{l} \sum_{m}\left[\frac{(l+m) b_{l m}}{\sum_{l} \sum_{m}(l+m) b_{l m}}\right] c_{l m}$

where $l$ and $m$ are indices for the number of maintenance and non-maintenance shopping categories, respectively, $(l=0,1,2$ and $m=0,1,2,3,4$ in the application context under 
consideration), $b_{l m}$ is the expected number of individuals who make $l$ maintenance stops and $m$ other (non-maintenance) stops, and $c_{l m}$ is the percentage aggregate change in each $(l, m)$ stop category. The results show that the independent model underestimates the increase in shopping stops due to an increase in full-time employed adults by about $16 \%$. It also underestimates the increase in shopping stops due to an increase in internet shoppers by about $22 \%$.

\section{SUMMARY AND CONCLUSIONS}

This paper has examined the activity participation behavior of individuals over the weekend in the spirit of an activity-based travel modeling approach. Specifically, the paper has modeled the frequency of participation of individuals in seven out-of-home activity purposes over the weekend: physically active recreation, physically inactive recreation, maintenance shopping, other shopping, personal business, community activities, and pick-up/drop-off activities. The focus on weekend activity participation is motivated by the increasing and substantial contribution of weekend travel to overall weekly travel as well as by the relatively little attention on weekend travel in the travel demand literature. The model of frequency of stops by activity type in the current paper can be viewed as one component of a larger weekend activity-travel pattern modeling system for forecasting weekend travel patterns using a microsimulation framework.

The methodology proposed and applied in the paper is a multivariate mixed ordered response logit (MMORL) model, where a normal multivariate mixing distribution is used to generate correlation in the unobserved terms affecting the propensity to participate in the different activity purposes. The model parameters are estimated using a simulated maximum likelihood method using Halton draws. 
The MMORL model is applied to study weekend stop-making patterns using the 2000 San Francisco Bay area travel survey. The analysis results indicate the important effects of household sociodemographics (income, household structure, and bicycle ownership), individual sociodemographics (age, employment status, gender, and availability of driver's license), internet use, location effects, and day of week/seasonal effects. Interestingly, the results show that motorized vehicle ownership and urban form characteristics of the individual's neighborhood (land-use mix and density) do not have a statistically significant effect on stop-making propensity for any of the activity purposes. The lack of effects of these variables may be due to self-selection of individuals and households into neighborhoods based on their travel preferences. That is, individuals and households may locate themselves based on their motorized vehicle ownership preferences and mobility preferences. For example, individuals and households who are not able to, or choose not to, own vehicles will likely locate themselves in areas with good transit service in the Bay area, so that their activity participation desires are relatively unaffected by vehicle ownership. A clear need from this hypothesis is to estimate joint models of residential choice, vehicle ownership, and activity participation rates in the future. Of course, the lack of effects of urban form characteristics may also be a result of the use of rather aggregate spatial units (i.e., zones) as the basis for computing location characteristics, which points to the need for testing of the effects of location attributes using a finer spatial resolution.

In addition to the effects of several variables on stop-making, the model also indicates the significant presence of unobserved dependencies among the propensities to participate in different activity purposes. Specifically, there is (a) substitution in participation between physically active recreation and the more sedentary discretionary activities (i.e., physically inactive recreation and non-maintenance shopping), (b) complementary effects between 
physically inactive recreation and all other activity types except physically active recreation and pick-up/drop-off activities, (c) complementarity in participation in the two shopping activity types (maintenance and non-maintenance), and (d) complementary effects between community and pick-up/drop-off activities. Accommodating these unobserved discrepancies leads to a statistically superior data fit in the empirical context of this study and also provides useful insights into competitiveness patterns among the many activity types.

The MMORL model is applied to evaluate the effect of changes in full-time employment and internet use for shopping “over time”. The results from this analysis reflect the importance of capturing dependencies among activity type participation propensities.

An important area for future research in the context of the current paper is the accommodation of interactions in activity participation among individuals within a household. Individuals within households interact to satisfy and meet personal and household maintenance needs (Bhat and Koppelman, 1999; Srinivasan and Bhat, 2004), enjoy companionship and undertake activities jointly (Wen and Koppelman, 2000; Gliebe and Koppelman, 2002; Zhang et al., 2002; Fujii et al., 1999; Scott and Kanaroglou, 2002), share a household vehicle, and serve household members with restricted mobility (Srinivasan and Bhat, 2004). All of these factors influence activity-travel patterns and schedules of household members. For example, "serve passenger” activity could impose spatial and temporal constraints on the overall activity-pattern of individuals (Kitamura, 1983). Models that fail to recognize these interpersonal interactions may result in erroneous predictions of changes in activity-travel patterns due to changes in landuse, transportation system, and demographic characteristics (Scott and Kanaroglou, 2002; Vovsha et al., 2003). 


\section{ACKNOWLEDGEMENTS}

The authors would like to thank Ken Vaughn and Chuck Purvis of the Metropolitan Transportation Commissions (MTC) in Oakland for providing help with data related issues. This research was funded, in part, by a grant from the Bureau of Transportation Statistics (BTS). The authors are grateful to Lisa Weyant for her help in typesetting and formatting this document. 6 anonymous reviewers provided helpful comments on an earlier version of the paper. 


\section{REFERENCES}

Arentze, T. A., and H. J. P. Timmermans (2004). A learning-based transportation oriented simulation system. Transportation Research Part B, 38(7), 613-633.

Bhat, C.R. (2001). Quasi-random maximum simulated likelihood estimation of the mixed multinomial logit model. Transportation Research Part B, 35, 677-693.

Bhat, C.R., and R. Gossen (2004). A mixed multinomial logit model analysis of weekend recreational episode type choice. Forthcoming, Transportation Research Part B.

Bhat, C.R., and F. S. Koppelman (1999). A retrospective and prospective survey of time-use research. Transportation, 26(2), 119-139.

Bhat, C.R., and A. Lockwood (2004). On distinguishing between physically active and physically passive episodes and between travel and activity episodes: An analysis of weekend recreational participation in the San Francisco Bay area. Forthcoming, Transportation Research Part B.

Bhat, C. R., and R. Misra (2001). Comprehensive activity travel pattern modeling system for nonworkers with empirical focus on organization of activity episodes. Transportation Research Record 1777, TRB, National Research Council, Washington, D.C., 16-24.

Bhat, C. R., and S. K. Singh (2000). A comprehensive daily activity travel generation model system for workers. Transportation Research Part A, 34(1), 1-22.

Bowman, J.L., and M.E. Ben-Akiva (2000). Activity-based disaggregate travel demand model system with activity schedules. Transportation Research Part A, 35, 1-28.

Casas, J., Zmud, J., and S. Bricka (2001). Impact of shopping via internet on travel for shopping purposes. Presented at the $80^{\text {th }}$ Annual Transportation Research Board Meeting, Washington D.C., January.

Castiglione, J., Freedman, J., and M. Bradley (2003). A systematic investigation of variability due to random simulation error in an activity-based micro-simulation forecasting model. Presented at the $82^{\text {nd }}$ Annual Transportation Research Board Meeting, Washington D.C., January.

Federal Highway Administration and Bureau of Transportation Statistics (1995). Nationwide Personal Transportation Survey Results.

http://www-cta.ornl.gov/npts/1995/doc/index.shtml. Accessed May 1, 2002.

Fujii, S., Kitamura, R., and K. Kishizawa (1999). Analysis of individuals’ joint activity engagement using a model system of activity-travel behavior and time use. Transportation Research Record, 1676, 11-19.

Gliebe, J. P., and F. S. Koppelman (2002). A model of joint activity participation between household members. Transportation, 29, 49-72.

Hajivassiliou, V.A. and P.A. Ruud (1994). Classical estimation methods for LDV models using simulations. Handbook of Econometrics, IV, R. Engle and D. McFadden, eds, Elsevier, New York, 2383-2441. 
Hamed, M.M., and F.L. Mannering (1993). Modeling travelers' postwork activity involvement: toward a new methodology. Transportation Science, 27(4), 381-394.

Kitamura, R. (1983). Serve passenger trips as a determinant of travel behavior. Recent Advances in Travel Demand Analysis, edited by S. Carpenter and P. Jones, 137-162.

Kitamura, R., and S. Fujii (1998). Two computational process models of activity travel behavior. Theoretical Foundations of Travel Choice Modeling, T. Garling, T. Laitila, and K. Westin, eds, Elsevier Science, Oxford, England.

Lee, L-F. (1992). On the efficiency of methods of simulated moments and maximum simulated likelihood estimation of discrete response models. Econometric Theory, 8, 518-552.

Lockwood, A., Srinivasan, S. and C.R. Bhat (2003). From travel surveys to time-use surveys: the importance of collecting data on weekend activity-travel and in-home activity participation. Presentation made to the Texas Department of Transportation, June 2, 2003.

Mahmassani, H.S., S.G. Hatcher, and C.G. Caplice (1997). Daily variation of trip chaining, scheduling, and path selection behavior of work commuters. Understanding Travel Behavior as an Era of Change, P. Stopher and M. Lee-Gosselin eds, Elsevier Science, New York.

Mallett, W. J., and N. McGuckin (2000). Driving to distractions: recreational trips in private vehicles. Transportation Research Record, 1719, 267-272.

McKelvey, R.D., and W. Zavonia (1975). A statistical model for the analysis of ordinal-level dependent variables. Journal of Mathematical Sociology, 4, 103-120.

Misra, R., Bhat, C.R., and S. Srinivasan (2003). Continuous time representation and modeling framework for analysis of nonworker activity-travel patterns: tour and episode attributes. Transportation Research Record, 1831, 11-20.

MORPACE International, Inc. (2002). Bay Area Travel Survey Final Report. March 2002. ftp://ftp.abag.ca.gov/pub/mtc/planning/BATS/BATS2000/

Parsons Brinckerhoff Quade and Douglas, Inc. (2000). Comparative analysis weekday and weekend travel with NPTS integration for the RT-HIS: regional travel-household interview survey. Prepared for the New York Metropolitan Council and the North Jersey Transportation Planning Authority, February.

Pendyala, R. M., and K. G. Goulias (2002). Time use and activity perspectives in Travel behavior research. Transportation, 29(1), 1-4.

Pendyala, R.M., T. Yamamoto, and R. Kitamura (2002). On the formulation of time-space prisms to model constraints on personal activity-travel engagement. Transportation, 29(1), 73-94.

Scott, D.M., and P.S. Kanaroglou (2002). An activity-episode generation model that captures interactions between household heads: development and empirical analysis.

Transportation Research Part B, 36(10), 875-896. 
Srinivasan, S., and C.R. Bhat (2004). Modeling the generation and allocation of shopping activities in a household. Technical paper, Department of Civil Engineering, The University of Texas at Austin.

Strathman, J.G., K.J. Dueker, and J.S. Davis (1994). Effects of household structure and selected travel characteristics on trip chaining. Transportation, 21, 23-45.

Texas State Data Center \& The Center for Demographic and Socioeconomic Research and Education (2000). Projections of the Population of Texas and Counties in Texas by Age, Sex and Race/Ethnicity for 1990-2030. College Station, Texas A\&M University, http://txsdc.tamu.edu/cgi-bin/prjctn2000.cgi

U.S. Census Bureau (1999). Working at Home. Population Division, Journey to Work, and Migration Branch, http://www.census.gov/population/www/socdemo. Accessed May 1, 2002.

Vovsha, P., Peterson, E., and R. Donnelly (2003). Explicit modeling of joint travel by household members: statistical evidence and applied approach. Presented at the $82^{\text {nd }}$ Annual Meeting of the Transportation Research Board, Washington, D.C.

Waddell, P., M. Outwater, C. R. Bhat, and L. Blain (2002). Design of an integrated land use and activity-based travel model system for the Puget Sound region. Transportation Research Record, 1805, 108-118.

Wen, C. H., and F. S. Koppelman (2000). A conceptual and methodological framework for the generation of activity-travel patterns. Transportation, 27, 5-23.

Zhang, J., Timmermans, H., and A. Borgers (2002). A utility-maximizing model of household time use for independent, shared, and allocated activities incorporating group decision mechanisms. Presented at the $81^{\text {st }}$ Annual Meeting of the Transportation Research Board, Washington, D.C. 


\section{APPENDIX A}

Location type categories considered as physically active social/recreational activities
1. Aerobics
2. Aquatics Center
3. Archery
4. Ballet Class
5. Batting Cages
6. Bike Trail
7. Bowling
8. Camp
9. Convention Center
10. Field
11. Fitness Class/Center
12. Ice Rink
13. Indoor Recreation/Sports
14. Karate/Martial Arts Classes
15. Park/Community Garden
16. Pool/Swim Center
17. Running/Walking
18. Skating/Skiing
19. Soccer
20. Swimming Lessons
21. Tennis
22. Yacht club
23. YMCA/ Youth Club 


\section{LIST OF FIGURE}

Figure 1. Analysis Framework for Weekend Day Activity-Travel Patterns.

\section{LIST OF TABLES}

Table 1a.Table 1a. Percentage of Individuals in Each “\# of Episodes” Category by Activity Type (Both Weekend Days)

Table 1b. Percentage of Individuals in Each "\# Episodes" Category by Activity Type (Saturday)

Table 1c. Percentage of Individuals in Each "\# Episodes" Category by Activity Type (Sunday)

Table 2. Multinomial Mixed Ordered Response Logit Estimation Results

Table 3. Correlation in Unobserved Propensities Across Activity Types (t-statistics in parentheses)

Table 4. Impact of Changes on Number of Maintenance and Other (Non-Maintenance) Stops 


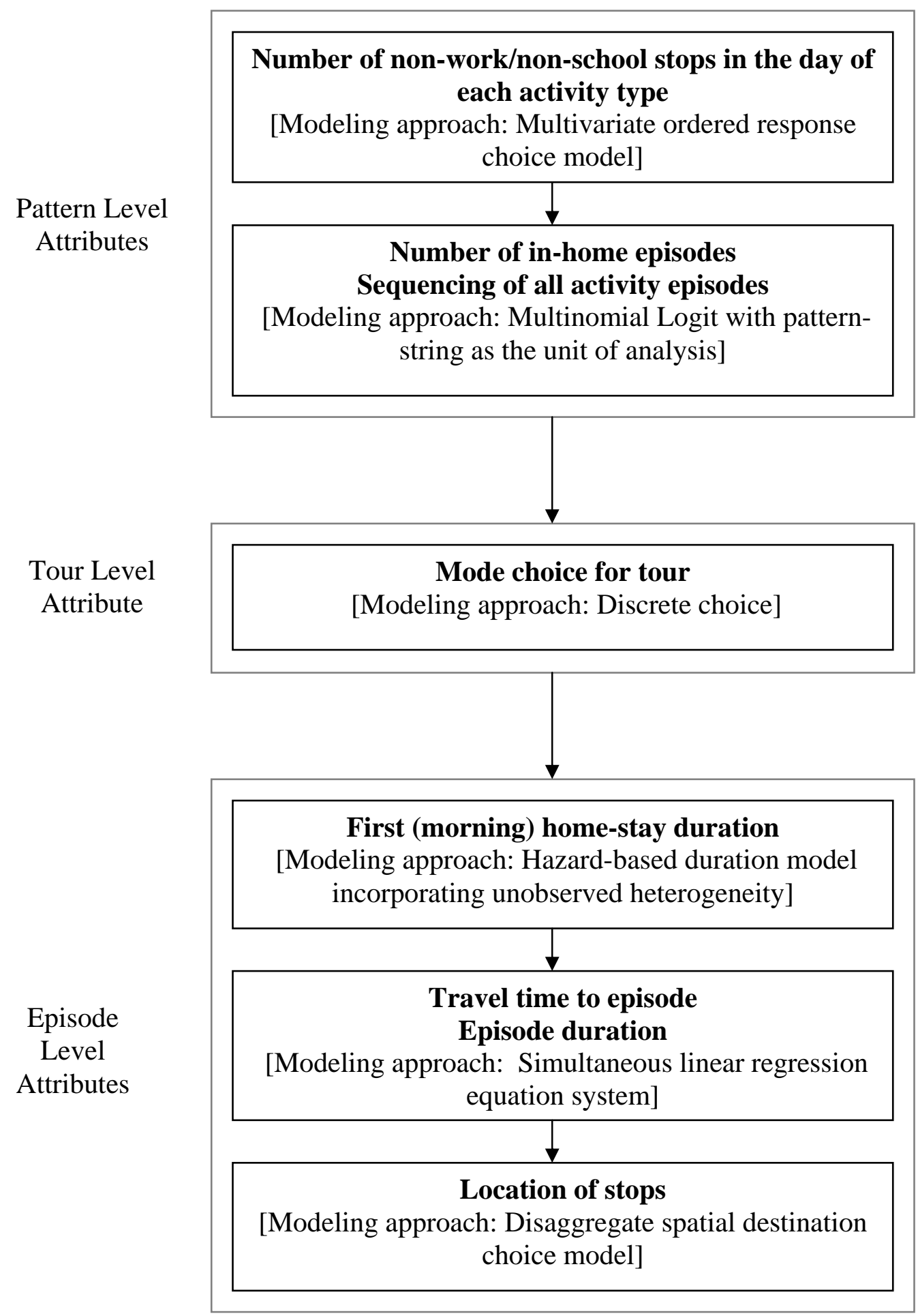

Source: Modified from Bhat and Misra (2001).

Figure 1. Analysis Framework for Weekend Day Activity-Travel Patterns. 
Table 1a. Percentage of Individuals in Each “\# of Episodes” Category by Activity Type (Both Weekend Days)

\begin{tabular}{|c|c|c|c|c|c|c|c||}
\hline \hline \# Episodes & $\begin{array}{c}\text { Physically active } \\
\text { recreation }\end{array}$ & $\begin{array}{c}\text { Physically inactive } \\
\text { recreation }\end{array}$ & $\begin{array}{c}\text { Maintenance } \\
\text { shopping }\end{array}$ & $\begin{array}{c}\text { Other } \\
\text { shopping }\end{array}$ & $\begin{array}{c}\text { Personal } \\
\text { business }\end{array}$ & $\begin{array}{c}\text { Community } \\
\text { activities }\end{array}$ & $\begin{array}{c}\text { Pick-up or } \\
\text { drop-off }\end{array}$ \\
\hline \hline 0 & 89.2 & 50.9 & 83.9 & 72.1 & 88.4 & 88.7 & 89.4 \\
1 & 9.9 & 30.0 & 14.2 & 20.3 & 9.8 & 10.4 & 6.1 \\
2 & 0.9 & 12.3 & 1.9 & 5.8 & 1.5 & 0.9 & 3.6 \\
3 & & 4.8 & & 1.4 & 0.3 & & 0.9 \\
4 & & 1.4 & & 0.4 & & & \\
$>=5$ & & 0.6 & & & & & \\
\hline
\end{tabular}

Table 1b. Percentage of Individuals in Each "\# Episodes" Category by Activity Type (Saturday)

\begin{tabular}{|c|c|c|c|c|c|c|c|}
\hline \# Episodes & $\begin{array}{l}\text { Physically active } \\
\text { recreation }\end{array}$ & $\begin{array}{c}\text { Physically inactive } \\
\text { recreation }\end{array}$ & $\begin{array}{l}\text { Maintenance } \\
\text { shopping }\end{array}$ & $\begin{array}{c}\text { Other } \\
\text { shopping }\end{array}$ & $\begin{array}{l}\text { Personal } \\
\text { business }\end{array}$ & $\begin{array}{l}\text { Community } \\
\text { activities }\end{array}$ & $\begin{array}{l}\text { Pick-up or } \\
\text { drop-off }\end{array}$ \\
\hline 0 & 88.3 & 48.0 & 84.0 & 70.1 & 86.2 & 94.8 & 88.4 \\
\hline 1 & 11.0 & 31.3 & 14.4 & 21.1 & 11.4 & 4.7 & 6.6 \\
\hline 2 & 0.7 & 12.4 & 1.6 & 6.8 & 2.0 & 0.5 & 3.8 \\
\hline 3 & & 6.1 & & 1.6 & 0.4 & & 1.2 \\
\hline 4 & & 1.6 & & 0.4 & & & \\
\hline$>=5$ & & 0.6 & & & & & \\
\hline
\end{tabular}

Table 1c. Percentage of Individuals in Each "\# Episodes" Category by Activity Type (Sunday)

\begin{tabular}{|c|c|c|c|c|c|c|c||}
\hline \# Episodes & $\begin{array}{c}\text { Physically active } \\
\text { recreation }\end{array}$ & $\begin{array}{c}\text { Physically inactive } \\
\text { recreation }\end{array}$ & $\begin{array}{c}\text { Maintenance } \\
\text { shopping }\end{array}$ & $\begin{array}{c}\text { Other } \\
\text { shopping }\end{array}$ & $\begin{array}{c}\text { Personal } \\
\text { business }\end{array}$ & $\begin{array}{c}\text { Community } \\
\text { activities }\end{array}$ & $\begin{array}{c}\text { Pick-up or } \\
\text { drop-off }\end{array}$ \\
\hline \hline 0 & 90.3 & 54.6 & 83.8 & 74.5 & 91.3 & 81.0 & 90.7 \\
1 & 8.7 & 28.3 & 14.0 & 19.4 & 7.7 & 17.5 & 5.4 \\
2 & 1.0 & 12.1 & 2.2 & 4.5 & 0.9 & 0.1 & \\
3 & & 3.2 & & 1.3 & & & \\
4 & & 1.3 & & 0.3 & & & \\
$>=5$ & & 0.5 & & & & & \\
\hline
\end{tabular}


Table 2. Multinomial Mixed Ordered Response Logit Estimation Results

\begin{tabular}{|c|c|c|c|c|c|c|c|c|c|c|c|c|c|c|}
\hline \multirow[t]{2}{*}{ Variable } & \multicolumn{2}{|c|}{$\begin{array}{c}\text { Physically active } \\
\text { recreation }\end{array}$} & \multicolumn{2}{|c|}{$\begin{array}{c}\text { Physically inactive } \\
\text { recreation }\end{array}$} & \multicolumn{2}{|c|}{$\begin{array}{c}\text { Maintenance } \\
\text { shopping }\end{array}$} & \multicolumn{2}{|c|}{ Other shopping } & \multicolumn{2}{|c|}{ Personal business } & \multicolumn{2}{|c|}{$\begin{array}{c}\text { Community } \\
\text { activities }\end{array}$} & \multicolumn{2}{|c|}{$\begin{array}{c}\begin{array}{c}\text { Pick-up or } \\
\text { drop-off }\end{array} \\
\text { (n) }\end{array}$} \\
\hline & Param. & t-stat & Param. & t-stat & Param. & t-stat & Param. & t-stat & Param. & t-stat & Param. & t-stat & Param. & t-stat \\
\hline $\begin{array}{l}\text { Household sociodemographics } \\
\text { Income variables }\end{array}$ & & & & & & & & & & & & & & \\
\hline Less than $50 \mathrm{~K}$ (base category) & - & - & - & - & - & - & - & - & - & - & - & - & - & - \\
\hline 50 to $75 \mathrm{~K}$ & - & - & 0.2949 & 3.31 & - & - & 0.3605 & 3.90 & - & - & - & - & 0.3126 & 2.36 \\
\hline 75 to $115 \mathrm{~K}$ & - & - & 0.5311 & 6.18 & - & - & 0.3605 & 3.90 & - & - & - & - & 0.3126 & 2.36 \\
\hline Greater than $115 \mathrm{~K}$ & - & - & 0.6409 & 6.01 & - & - & 0.6071 & 4.91 & - & - & - & - & 0.5661 & 3.39 \\
\hline Household structure (specific to adults) & & & & & & & & & & & & & & \\
\hline Other household types (base category) & - & - & - & - & - & - & - & - & - & - & - & - & - & - \\
\hline Single parent household & 1.0036 & 2.48 & 0.4569 & 1.54 & - & - & - & - & - & - & - & - & - & - \\
\hline Nuclear Family & 0.6874 & 4.36 & 0.1867 & 2.05 & - & - & - & - & - & - & - & - & - & - \\
\hline Single individual household & 0.4677 & 2.66 & 0.4073 & 4.02 & 0.3572 & 3.10 & 0.1742 & 1.52 & - & - & - & - & - & - \\
\hline Couple family & 0.2983 & 2.00 & 0.1679 & 2.11 & - & - & 0.1035 & 1.21 & - & - & - & - & - & - \\
\hline Presence of children 5-10 years in household & - & - & - & - & -0.2771 & -1.98 & - & - & -0.3450 & -2.20 & 0.2997 & 1.85 & 0.7267 & 5.41 \\
\hline Presence of children 11-15 years in household & - & - & - & - & - & - & - & - & - & - & 0.5024 & 3.26 & 0.6989 & 5.38 \\
\hline Presence of bicycles in the household & & & & & & & & & & & & & & \\
\hline Specific to adults & 0.3386 & 2.77 & 0.2759 & 3.78 & - & - & - & - & - & - & - & - & - & - \\
\hline Specific to children & 1.2985 & 2.23 & - & - & - & - & - & - & - & - & - & - & - & - \\
\hline Individual sociodemographics & & & & & & & & & & & & & & \\
\hline $\begin{array}{l}\text { Age } \\
\text { Child (age less than } 16 \text { years) }\end{array}$ & & & & & -10136 & -6.13 & - & & & & & & & \\
\hline 16 to 21 years & $\begin{array}{c}0.6310 \\
-\end{array}$ & 3.76 & - & - & $\begin{array}{l}-1.0136 \\
-0.5962\end{array}$ & $\begin{array}{l}-0.13 \\
-260\end{array}$ & -0.5853 & -294 & - & - & $\begin{array}{r}-0.5985 \\
-07975\end{array}$ & -3.25 & 1.1347 & 2.88 \\
\hline 22 to 30 years & - & - & - & - & -0.0302 & -2.00 & $\begin{array}{c}-0.5853 \\
-\end{array}$ & -2.94 & - & - & $\begin{array}{l}-0.79 / 5 \\
-1.2129\end{array}$ & $\begin{array}{l}-2.90 \\
-4.93\end{array}$ & $\begin{array}{c}0.3 / 13 \\
-\end{array}$ & $\begin{array}{l}1.03 \\
-\end{array}$ \\
\hline 31 to 50 years & - & - & - & - & - & - & - & - & - & - & -0.7452 & -4.04 & 0.2420 & 1.95 \\
\hline 51 to 65 years & - & - & - & - & - & - & - & - & - & - & -0.5367 & -3.03 & & \\
\hline Greater than 65 years (base category) & - & - & - & - & - & - & - & - & - & - & - & - & - & - \\
\hline Employment status (specific to adults) & & & & & & & & & & & & & & \\
\hline Full time employed & - & - & - & - & - & - & 0.5555 & 6.64 & 0.3435 & 3.03 & -0.2783 & -2.20 & - & - \\
\hline Part time employed & - & - & - & - & - & - & - & - & 0.3435 & 3.03 & - & - & - & - \\
\hline Not employed (base category) & - & - & - & - & - & - & - & - & - & - & - & - & - & - \\
\hline Weekend work/school participation characteristics & & & & & & & & & & & & & & \\
\hline Participated in work/school activity & - & - & - & - & - & - & - & - & - & - & -0.6409 & -2.20 & 0.6683 & 4.61 \\
\hline Work/school duration between 4-8 hours & -1.1104 & -3.79 & -0.6570 & -4.72 & - & - & -0.7471 & -4.36 & -0.6209 & -2.60 & -0.9808 & -2.22 & - & - \\
\hline Work/school duration greater than 8 hours & -1.4768 & -5.04 & -1.6047 & -11.24 & -1.1253 & -5.37 & -1.9780 & -10.08 & -1.2253 & -5.03 & -1.7847 & -3.42 & -0.7646 & -3.40 \\
\hline Race (specific to adults) & & & & & & & & & & & & & & \\
\hline Hispanic & - & - & - & - & -0.5440 & -2.30 & - & - & - & - & - & - & - & - \\
\hline Asian & - & - & - & - & - & - & - & - & - & - & - & - & 0.4797 & 2.90 \\
\hline Other races (base category) & 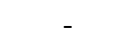 & - & - & - & 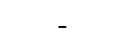 & - & - & - & - & - & - & - & - & r \\
\hline Other Individual sociodemographics & & & & & & & & & & & & & & \\
\hline Has driver's license & - & - & - & - & - & - & 0.1437 & 1.18 & 0.3796 & 2.35 & - & - & 1.1423 & 3.28 \\
\hline Physically challenged & -0.4668 & -1.45 & - & - & -0.5830 & -2.20 & - & - & - & - & - & - & - & - \\
\hline Female & - & - & - & - & 0.2407 & 2.66 & 0.3813 & 4.93 & 0.3157 & 3.15 & - & - & 0.2881 & 2.66 \\
\hline
\end{tabular}


Table 2. (Continued)

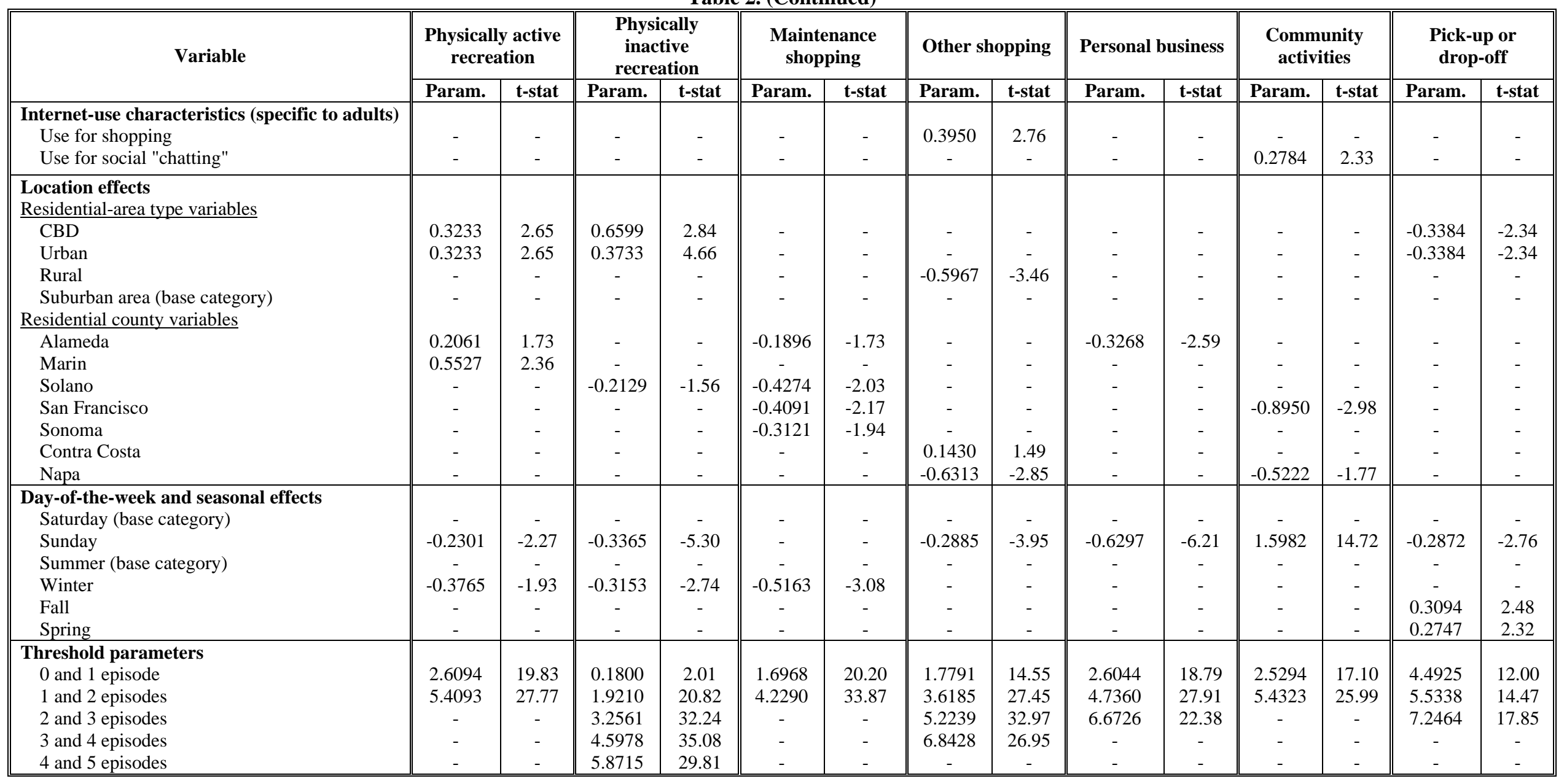


Table 3. Correlation in Unobserved Propensities Across Activity Types ( $t$-statistics in parentheses)

\begin{tabular}{|l|c|c|c|c|c|c|c|}
\hline \multicolumn{1}{|c|}{ Activity Type } & $\begin{array}{c}\text { Physically } \\
\text { active } \\
\text { recreation }\end{array}$ & $\begin{array}{c}\text { Physically } \\
\text { inactive } \\
\text { recreation }\end{array}$ & $\begin{array}{c}\text { Maintenance } \\
\text { shopping }\end{array}$ & $\begin{array}{c}\text { Other } \\
\text { shopping }\end{array}$ & $\begin{array}{c}\text { Personal } \\
\text { business }\end{array}$ & $\begin{array}{c}\text { Community } \\
\text { activities }\end{array}$ & $\begin{array}{c}\text { Pick-up or } \\
\text { drop-off }\end{array}$ \\
\hline $\begin{array}{l}\text { Physically active } \\
\text { recreation }\end{array}$ & 1 & -0.289 & 0 & -0.372 & 0 & 0 & 0 \\
$(-2.62)$ & $(-)$ & $(-3.06)$ & $(-)$ & 0 & $(-)$ \\
\hline $\begin{array}{l}\text { Physically inactive } \\
\text { recreation }\end{array}$ & & 1 & 0.064 & 0.107 & 0.308 & $(2.82)$ & $(-)$ \\
\hline $\begin{array}{l}\text { Maintenance } \\
\text { shopping }\end{array}$ & & & $(0.67)$ & $(1.34)$ & 0.445 & 0.022 & 0 \\
$(-)$
\end{tabular}


Table 4. Impact of Changes on Number of Maintenance and Other (Non-Maintenance) Stops

\begin{tabular}{|c|c|c|c|c|c|c|}
\hline \multirow{3}{*}{ Change } & \multirow{3}{*}{$\begin{array}{c}\text { Number of } \\
\text { maintenance } \\
\text { shopping stop } \\
\text { categories }\end{array}$} & \multirow{2}{*}{\multicolumn{5}{|c|}{$\begin{array}{c}\text { Percentage change in each maintenance and non-maintenance stop categories } \\
\text { Number of other (non-maintenance) shopping stop categories }\end{array}$}} \\
\hline & & & & & & \\
\hline & & 0 & 1 & 2 & 3 & 4 \\
\hline \multirow{3}{*}{$\begin{array}{l}\text { Increase in full-time } \\
\text { employed adults }\end{array}$} & 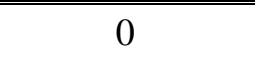 & -0.94 & 1.00 & 2.75 & 2.99 & 3.22 \\
\hline & 1 & -0.89 & 1.11 & 2.45 & 3.16 & 3.41 \\
\hline & 2 & -0.69 & 1.55 & 2.31 & 3.33 & 3.50 \\
\hline \multirow{3}{*}{$\begin{array}{l}\text { Increase in internet-use for } \\
\text { shopping }\end{array}$} & 0 & -1.26 & 1.50 & 2.84 & 3.45 & 3.63 \\
\hline & 1 & -1.19 & 1.70 & 2.91 & 3.43 & 3.59 \\
\hline & 2 & -1.07 & 2.60 & 3.73 & 4.14 & 4.26 \\
\hline
\end{tabular}

